\title{
Organoleptic characterization and PAH content of salmon (Salmo salar) fillets smoked according to four industrial smoking techniques
}

\author{
Vincent Varlet ${ }^{1}$, Thierry Serot ${ }^{1 *}$, Camille Knockaert ${ }^{2}$, Josiane Cornet $^{2}$, Mireille Cardinal ${ }^{2}$, \\ Fabrice Monteau ${ }^{3}$, Bruno Le Bizec ${ }^{3}$, Carole Prost ${ }^{1}$ \\ ${ }^{1}$ ENITIAA, Laboratoire de Biochimie Alimentaire et Industrielle, Rue de la Géraudière, BP 82225, Nantes Cedex \\ 3, France \\ 2IFREMER, Laboratoire STAM, Rue de l'Ile d'Yeu, BP 21105, 44311 Nantes Cedex 3, France \\ ${ }^{3}$ Laboratoire d'Etudes des Résidus et Contaminants dans les Aliments (LABERCA), Ecole Nationale Vétérinaire \\ de Nantes (ENVN), Route de Gachet, BP 50707, 44307, Nantes Cedex 3, France
}

*Correspondence to Thierry Serot; ENITIAA, Laboratoire de Biochimie Alimentaire et Industrielle, Rue de la Géraudière, BP 82225, Nantes Cedex 3, France ; serot@enitiaa-nantes.fr

\begin{abstract}
:
Four industrial processes for smoking food were studied through their effects on the organoleptic properties of smoked salmon and on the occurrence of 20 polycyclic aromatic hydrocarbons (PAHs) known as being contaminants of smoking processes. The contamination by PAHs of the food might be measured by their corresponding toxic equivalent quantity (TEQ) expressed in $\mu \mathrm{g} \mathrm{kg}-1$. The results show a significant correlation between the smoking process parameters, the odour of the smoked fish and the presence of PAHs. Smouldering, thermostated plates and friction smoking processes allow smoked fish with very close odorant characteristics to be obtained. However, differences of pyrolysis temperature (between 380 and $500{ }^{\circ} \mathrm{C}$ ) causes significant differences of PAHs concentration even if the contents are under the legal threshold concerning benzo(a)pyrene $(5 \mu \mathrm{g} \mathrm{kg}-1)$. Smoked fish obtained by liquid smoke vaporisation presented the lowest level of PAHs but benzo(a)pyrene concentration is nevertheless important. The odours brought by the liquid smoke process are more cold smoke and vegetal/green than the other techniques, which are smokier and fishier. Copyright $\odot$ 2007 Society of Chemical Industry.
\end{abstract}

Keywords: smoking process $\bullet$ smoke generation $\bullet \mathrm{PAH} \bullet$ organoleptic properties 


\section{Introduction}

Smoking is one of the oldest food preservation methods. It consists in the application of wood smoke on food. However, this process is, nowadays, more used to give their organoleptic characteristics to smoked foods than for its preservation qualities. The industry has developed four main types of smoking process very dependent of the wood smoke generation technique ${ }^{1}$. In 2002, the proportion of smoking processes for fish in Europe was close to $65 \%$ for smouldering, $30 \%$ for thermostated plates, and the rest for friction and liquid smoke vaporisation. Smouldering, thermostated plates and friction processes allow to produce smoke by pyrolysis of wood sawdust, wood chips and wood log respectively ${ }^{2}$. According to the nature of the wood and to the parameters of pyrolysis (temperature, moisture, oxygen ...), the wood smoke is very different from an aromatic point of view ${ }^{3}$. In recent decades, liquid smoke vaporization was used. It consists in the atomization (vaporization) of liquid smoke obtained from condensation of wood smoke. This process leads to an important diversity of products. Besides, the control of smoke contaminants is easier in liquid smoke in order to avoid polycyclic aromatic hydrocarbons (PAHs) ${ }^{4}$. These carcinogenic molecules are produced during pyrolysis of organic material such as wood. During the production of liquid smoke, some steps allow to reduce the PAH rate in the final liquid smoke whereas it is not easy to control the PAH rate during traditional smoke generation. Moreover, the storage of liquid smoke in polyethylene flasks can also reduce PAHs concentration ${ }^{5,6}$. Nevertheless, the legal threshold of benzo(a)pyrene is lower for the smoke flavourings additives than for the other smoking procedures. Concerning smoking techniques applying wood pyrolysis, the modern facilities have allowed to separate the smokehouse and the wood smoke generator. However, even if food is placed in a separate chamber from the wood smoke generator and even if wood smoke is cleaned by various electrostatic filters or smoke washing, PAHs occurrence can be minimized but not totally controlled and suppressed ${ }^{7}$. A better knowledge of smoking parameters, particularly smoke production parameters could allow to optimize the organoleptic characteristics of the smoked food and to obtain safety products

Therefore, the aim of this study is to compare the effects of four smoking techniques on the organoleptic characteristics of smoked salmon fillets with a simultaneous evaluation of the PAHs contents. 


\section{Materials and methods}

\section{Raw material and reagents}

Ultrapure water was obtained with a MilliQ ${ }^{\circledR}$ system. All solvents for PAH analysis were of analytical or HPLC grade and purchased from SDS (Peypin, France) except toluene and tetrahydrofurane from Fluka (Buchs, Switzerland). The phenyl-2,3-dimethyl-4-amino-5pyrazolone came from Merck (Darmstadt, Germany) and the phenolic standard solution at 1 mg/L (Prolabo, Fontenay-sous-bois, France).

ENVI Chrom P cartridges of $6 \mathrm{~mL}, 0,50 \mathrm{~g}$ bonded phase of styrenedivinylbenzene resin were obtained from Supelco (Bellefonte, USA). All mixes of PAH were from LGC Promochem (Wessel, Germany) except benzo(a)anthracene, chrysene and benzo(a)pyrene which were obtained from Chiron (Trondheim, Norway).

Beech wood sawdusts came from SPPS (Paris, France) and beech wood log from Bourdeau (Nozay, France)

\section{Fish processing}

Salmons (Salmo salar) reared in Norway were purchased from a seafood wholesaler (Nantes, France). The time between the capture and the filleting was less than one week. Nine gutted fishes of $3 \sim 4 \mathrm{~kg}$ of a same batch were received in a box in ice. They were directly filleted, trimmed and put on grids in a cold chamber at $+3^{\circ} \mathrm{C}$ for $2 \mathrm{hrs}$. All the fillets were about $1 \mathrm{~kg}$. Biochemical analysis of water and $\mathrm{NaCl}$ content have been carried out before smoking. The rate of water was $65 \mathrm{~g} / 100 \mathrm{~g}$ and the rate of $\mathrm{NaCl}$ was $0.20 \mathrm{~g} / 100 \mathrm{~g}$. Dry matter content was analysed by oven drying of $2 \mathrm{~g}$ of smoked salmon at $105^{\circ} \mathrm{C}$ until a constant weight was reached and salt content was measured with Chloride Analyser 926 (Corning, Halstead, UK). Next, they were hand-salted with refined salt (Salins du Midi, France) and left for $3 \mathrm{hrs}$ at $+12^{\circ} \mathrm{C}$ before being rinsed on grids with water $\left(15^{\circ} \mathrm{C}\right)$ and stored at $3^{\circ} \mathrm{C}$ for $18 \mathrm{hrs}$ until smoking.

Concerning PAHs evaluation, two smokehouse temperatures were studied (32 and $22{ }^{\circ} \mathrm{C}$ ). Before smoking, a drying step was carried by putting the fillets in the smokehouse at $18{ }^{\circ} \mathrm{C}$ during 15 min in order to standardize the internal temperature at $8{ }^{\circ} \mathrm{C}$ for all the samples. Then, at the beginning of the smoking process, fillets had the same inner temperature whatever the smokehouse temperature. After smoking the fillets were stored during less than one week at $+2{ }^{\circ} \mathrm{C}$ prior sensorial analysis. The medium parts of smoked fillets (about $200 \mathrm{~g}$ ) were put at $-80{ }^{\circ} \mathrm{C}$ and freeze-dried for PAH analysis.

\section{Smoking equipment and procedures}

The smokehouse was an HMI Thirode (PC90 Model) device (Thirode, France), $1500 \times 1300 \times 2250$ mm with a capacity of $380 \mathrm{~kg}$, mounted on a trolley with 28 grids on which the fillets were deposited. For each smoking technique, the fillets were placed at the same level (grid numbers 10,12 and 14) at $20 \mathrm{~cm}$ of the door of the smokehouse. The air/smoke circulation was horizontal. Salmon fillets were swept by the smoke for 1,2 and 3 hours at a temperature of 22 and $32^{\circ} \mathrm{C}$. The exhaust valve opening was $1 / 3$ and closed for liquid smoke and the relative hygrometry was sat at $60 \%$. For each process except liquid smoke, the smoke was introduced in the smokehouse with a flow rate of $90 \mathrm{~m}^{3} / \mathrm{h}$. 
Concerning PAH evaluation, three fillets were put off the smokehouse each hour during three hours in order to measure the PAHs occurrence according to the time of smoking and the temperature of the smokehouse. Concerning sensorial assessment, only the fillets smoked during 3 hours at $32{ }^{\circ} \mathrm{C}$ were compared.

The smokehouse consists in a separate chamber from the wood smoke generators. The smoke is purified through filters and introduced in the smokehouse thermostated at the required temperature $\left(22\right.$ or $32^{\circ} \mathrm{C}$ ) through a tube which permits a decrease of smoke temperature until the smokehouse temperature.

\section{Smouldering parameters}

A generator (Thirode, France) produced smoke by pyrolysis (between 400 and $450{ }^{\circ} \mathrm{C}$ ) of beech sawdust using the smouldering method. The sawdust was poured onto an electrically heated ring and pyrolyzed. The pyrolysis temperature was determined with a probe placed onto the heated ring. The ring was heated only for the ignition period and was entertained further only by electric pulses. The pyrolysis was also maintained thanks to an air intake producing a continuous flow around the heated ring by a fan. The sawdust fell on the heated ring by gravity from a hopper. Introduction of sawdust was programmed every six minutes. The sawdust was before moistened and homogenized in order to obtain a moisture rate of $20 \%$.

\section{Thermostated plates parameters}

A generator $720 \times 1120 \times 1730 \mathrm{~mm}$ (Thirode, France) produced smoke by pyrolysis $\left(500{ }^{\circ} \mathrm{C}\right)$ of beech chips. The pyrolysis temperature was determined with a probe placed on the plates. A system spreads the chips on thermostated plates and the plates were cleaned after 3 minutes of combustion. The smoke was pulsed by a ventilator in order to obtain the same flow rate of smoke in the smokehouse than smouldering and friction.

\section{Friction parameters}

A generator type FR 1002 (Muvero, The Netherlands) produced smoke by friction $\left(380{ }^{\circ} \mathrm{C}\right)$ by pressing a beech log $(8 \times 8 \times 10 \mathrm{~cm})$ against a rotating friction wheel during 10 seconds and every 30 seconds. The pyrolysis temperature was determined with a probe placed into the log. The beech log is pressed pneumatically by means of a wood gripper with a pressure of 3,5 bars.

\section{Liquid smoke parameters}

Liquid smoke was purchased from a smoke flavouring manufacturer (France). It is a purified condensate of beech smoke. Liquid smoke is atomized by pressurized air in the smokehouse at ambient temperature. The vaporization device (Lutetia, France) allows to set the pressures of air and liquid smoke in order to obtain a consumption of liquid smoke of $1 \mathrm{~L} / \mathrm{h}$ as in industrial procedures. Liquid smoke was injected in the smokehouse during 2 minutes every 3 minutes. For this type of smoking process, the hygrometry of the smokehouse was sat at $70 \%$.

\section{Sensorial evaluation}


Sensorial evaluation smoked salmon odours were performed by a panel consisting of 20 subjects recruited in IFREMER laboratories and trained in fish sensorial analysis. Descriptive tests enabled the samples to be evaluated by their organoleptic characteristics. Sessions were performed in individual partitioned boxes equipped with a computerized system (Fizz, Biosystèmes, Couternon, France). The panellists were asked to evaluate the intensity of organoleptic descriptors (six for the odour and seven for the taste evaluation) on a continuous scale displayed on the computer screen, from « 0 » (low intensity » to « 10 » (high intensity). The descriptors used were chosen according to their efficiency to differentiate fish sample characteristics. Products were assigned 3-digit numbers and randomized. The average of the different marks was used to build the sensorial profiles of the different smoked salmons. Sensorial analysis occurs only on salmons smoked during three hours at $32{ }^{\circ} \mathrm{C}$.

\section{Total phenolic compounds analysis}

All the procedures for total phenolic compounds quantification have been already described in previous works ${ }^{8}$.

\section{PAH analysis ${ }^{9}$}

\section{Solid-Liquid extraction}

Two grams of freeze-dried fillet spiked with a mixture of the twenty ${ }^{13} \mathrm{C}$ PAH studied at 0.5 $\mu \mathrm{g} . \mathrm{kg}^{-1}$, considered as internal standards were homogenized in $40 \mathrm{~mL}$ of cyclohexane / ethyl acetate $(50: 50 ; \mathrm{v} / \mathrm{v})$ and shaked during $30 \mathrm{~min}$, then centrifuged at $5000 \mathrm{~g}, 30 \mathrm{~min}$ at $0{ }^{\circ} \mathrm{C}$. The liquid part was carefully isolated and evaporated to dryness under a gentle stream of nitrogen. The residue was dissolved in $6 \mathrm{~mL}$ of cyclohexane. PAH quantification was the result of the mean of measures carried out on three individual fillets smoked in the same conditions.

\section{SPE Clean-up procedure}

For the purification, the solid-phase extraction cartridges ENVI Chrom $\mathrm{P}$ cartridges of $6 \mathrm{~mL}$, 0,50 g bonded phase (Supelco, Bellefonte, USA) were conditioned with $5 \mathrm{~mL}$ of water, then 5 $\mathrm{mL}$ of methanol followed by $5 \mathrm{~mL}$ of cyclohexane. $6 \mathrm{~mL}$ of sample in cyclohexane were then introduced onto the cartridge and washed with $3 \mathrm{~mL}$ of cyclohexane in order to remove interferences due to fat matter. The PAHs were eluted with $12 \mathrm{~mL}$ of a mixture of cyclohexane and ethyl acetate (50:50;v/v) and after, evaporated to dryness under nitrogen stream. Residue was finally dissolved in $40 \mu \mathrm{L}$ of toluene.

\section{GC/MS/MS analysis}

For GC/MS/MS experiments, an HP-6890 gas chromatograph (Agilent Technologies, Palo-Alto, USA) was coupled to a MS-MS Micromass Quattro Micro mass spectrometer (Waters Milford, USA). A glass insert, $4 \mathrm{~mm}$ i.d., loosely filled with silanized glass wool was used in the split/splitless mode GC injector $\left(280^{\circ} \mathrm{C}\right)$. The GC column Zebron was a ZB-5MS $30 \mathrm{~m} \times 0,25$ mm i.d., film thickness 0,25 $\mu \mathrm{m}$ (Phenomenex, Torrance, USA). The GC oven temperature was maintained at $110^{\circ} \mathrm{C}$ for $1 \mathrm{~min}$ after injection then programmed at $20^{\circ} \mathrm{C} \cdot \mathrm{min}^{-1}$ to $240^{\circ} \mathrm{C}$, then at 5 ${ }^{\circ} \mathrm{C}$. $\min ^{-1}$ to $340^{\circ} \mathrm{C}$. Helium was used as carrier gas. Electron ionization was used and SRM (Selected Reaction Monitoring) was selected as acquisition technique. Monitored ions were those 
of PAHs from fluorene to benzo(g,h,i)perylene listed amongst the US EPA 16 priority pollutants with in addition, cyclopenta(c,d)pyrene, 5-methylchrysene, benzo(j)fluoranthene and dibenzo(a,l)pyrene, dibenzo(a,e)pyrene, dibenzo(a,i)pyrene, dibenzo(a,h)pyrene. The last added PAHs were those recently recommended by the European Commission ${ }^{10}$. 


\section{Results}

\section{Economic approach of wood smoke generation}

Among the smoke generation techniques studied (Table 1), thermostated plates process is the mode that uses the weakest wood quantity but has the greatest electric consumption $(1.8 \mathrm{~kW} / \mathrm{h})$ due to the temperature of the plates which must be hold at $500{ }^{\circ} \mathrm{C}$. Smouldering technique involves more sawdust and generates ashes $(110 \mathrm{~g} / \mathrm{h})$ but the electric consumption is more than two times lower than in thermostated plates technique $(0.7 \mathrm{~kW} / \mathrm{h})$. Friction implies a similar quantity of wood pyrolyzed but ashes generated are nearly two times lower than in smouldering mode $(60 \mathrm{~g} / \mathrm{h})$. However, the price of the wood log is higher and the electric consumption also because the energy used to press the log against the rotating friction wheel must be consequent $(1.6 \mathrm{~kW} / \mathrm{h})$. Concerning liquid smoke atomization, the only cost is the price of the liquid smoke used but this process is the most expensive from the smoke production point of view (table 1).

Friction technique seems to be the more expensive smoking process applying generation of wood smoke by pyrolysis, and smouldering the cheapest. Even if liquid smoke process is not electricity-consuming, it is the most expensive technique.

\section{Organoleptic profiles and relation with total phenolic content}

\section{Odour analysis}

Two organoleptic characteristics, the odour and the taste, were studied and related to the total phenolic content. For the odour characterization, six descriptors were chosen for their suitability to describe smoked salmon. ("wood fire smoke" odour, cold smoke odour which is a little bitterer than wood fire smoke, butter, vegetal, salmon and herring-like odour).

The odour analysis results (Table 2) show that, except for the descriptor "herring-like" odour, the odours of fillets smoked by smouldering, thermostated plates and friction smoking modes are significantly different from the odours of fillets smoked by liquid smoke. These results illustrate the odorant similarity of fillets smoked with the three pyrolysis processes against the liquid smoke technique. Nevertheless, odorant differences between the three pyrolysis techniques can be observed especially on cold smoke, butter and salmon-like descriptors. These differences could be due to the differences of the temperature of pyrolysis of the wood. Indeed, according to the parameters of wood smoke generation, the nature and the quantity of odour-active compounds formed could be different. For example, from 400 to $500{ }^{\circ} \mathrm{C}$, the highest the temperature is, the strongest the pyrolysis of lignin is. Therefore, the phenolic and furannic compounds formation increases ${ }^{11}$. Similarly, it has previously been reported that the difference in smoke production temperature between friction $\left(350-380^{\circ} \mathrm{C}\right)$ and smouldering $\left(400-450^{\circ} \mathrm{C}\right)$ leads to a less advanced degradation of the wood with friction than with others higher temperature of pyrolysis methods ${ }^{12}$. Therefore, for friction, with a temperature of pyrolysis of $380{ }^{\circ} \mathrm{C}$ (Table 1), the smoke obtained could be less loaded in odorants responsible for the smoke odour and could less hide the butter odour of the fillets than thermostated plates $\left(500{ }^{\circ} \mathrm{C}\right)$ and as result, the butter odour is stronger than with thermostated plates ${ }^{13}$. Besides, this trend between processes applying high pyrolysis temperature (smouldering, thermostated plates) and processes with lower pyrolysis temperature (friction) was already been shown with in more, a stronger perception of smoke (cold ash, burnt tyre) odour of smouldering product ${ }^{14}$. Similar qualitative results are obtained herein 
except for the smoke perception. It could be certainly due to a weaker range of pyrolysis temperature because pyrolysis by friction technique was carried out at $380{ }^{\circ} \mathrm{C}$ instead of $350{ }^{\circ} \mathrm{C}$ and for smouldering at about $400{ }^{\circ} \mathrm{C}$ instead of $450{ }^{\circ} \mathrm{C}$. That is the reason why the perception of "wood fire smoke" odour of the three smoke generations by wood pyrolysis processes is close. The relative homogenity in smoky odours for the three processes could be related to the total phenolic content. Indeed, quantities of $1.33,1.29$ and $1.17 \mathrm{mg}$ of phenolic compounds reported to $100 \mathrm{~g}$ of smoked salmon are found for respectively, smouldering, thermostated plates and friction techniques. For liquid smoke, a quantity of phenolic contents of $0.95 \mathrm{mg} / 100 \mathrm{~g}$ is measured. The perception of "wood fire smoke" in the products treated with liquid smoke is nearly two times lower than for the three other processes.

Among the three processes applying wood pyrolysis, thermostated plates seem to be the most responsible for "cold smoke » odour. It could be due to the high temperature of the plates $\left(500{ }^{\circ} \mathrm{C}\right)$ which could favour the generation of phenolic but also of furannic compound in wood smoke ${ }^{15}$ because the total phenolic content is not sufficient to explain the little differences and especially, seems not to act in the perception of cold smoke odour. Indeed, product treated with liquid smoke are at least two times more "cold smoke" than the others products and has nevertheless the lowest total phenolic content. The « cold smoke » odour intensity of fish smoked by liquid smoke atomization is very important (5.04) whereas for the pyrolysis techniques the intensity is between 1.43 and 2.38. These observations are strengthened by a previous work ${ }^{16}$ which showed that salmon fillets smoked with liquid smoke appeared nearly two times « sooter " than fillets smoked with smouldering process and three times than thermostated plates process.

Concerning the « vegetal » odour, no significant difference is noticeable between fillets smoked according to smouldering, thermostated plates and friction methods. Only liquid smoke is very different. The important vegetal odour of smoked salmon treated by liquid smoke could be explained by the liquid smoke odour because it has been reported that smoke flavourings carry green/almond odour ${ }^{17}$. In smoked salmons treated with liquid smoke, stronger earthy and green odours have already been described by comparison to techniques applying wood pyrolysis ${ }^{14}$. This can strengthen our results because the products smoked by atomization are found nearly four times more « vegetal » than the products smoked by pyrolysis smoking techniques.

Finally, concerning «salmon-like » odour, no difference can be observed between the odour of fillets smoked with the three pyrolysis techniques even if smouldering seems to be more marked by the salmon-like odour than friction and thermostated plates. This trend has already been noticed in similar pyrolysis temperature conditions but with a smokehouse temperature of $22{ }^{\circ} \mathrm{C}$ with smouldering and thermostated plates ${ }^{16}$. As we worked with a smokehouse temperature of $32{ }^{\circ} \mathrm{C}$ and as we observe this trend, smouldering mode seems to bring odours more "fishy" than the two others techniques independently of the smokehouse temperature. For this descriptor, products treated with liquid smoke appear with a significantly weaker "salmon-like" odour. In a previous study, Cardinal et al ${ }^{16}$ have shown that fillets smoked with liquid smoke were characterized by "salmon-like » odour one time and a half weaker than the odour of fillets smoked by smouldering process (intensity of 2.3 for liquid smoke and 4.3 for smouldering). The other odours carried by liquid smoke to the salmon as "cold smoke" and "vegetal" are so strong that they could mask the own fishy odour of the smoked salmon flesh. The same remark could be formulated to explain the weaker perception of "butter" odour in products smoked with liquid smoke. Moreover, even if the smokehouse temperature was the same, the wood smoke arrives on the fillets at a temperature of about $80{ }^{\circ} \mathrm{C}$ before to be diluted in the smokehouse at $32{ }^{\circ} \mathrm{C}$. By comparison with liquid smoke which is vaporized at room temperature, the heat of the smoke used in the techniques applying wood pyrolysis can cause a stronger lipid oxidation during 
smoking process. This difference could lead to variations in the aroma profile of the smoked salmon obtained.

Liquid smoke gives to the smoked products odour characteristics which seem to be very different from the odours characteristics of products obtained with the three other techniques applying wood pyrolysis. The parameters of the smoking process by atomization of liquid smoke can be responsible of these odorant differences but the nature of the liquid smoke itself could be more certainly implied in these variations. Indeed, according to the wood nature, the conditions of liquid smoke generation processes, the liquid smokes can be very different in composition and odours.

\section{Taste evaluation}

The taste of the different smoked salmons was described with the same descriptors as for the odour characterisation with in more, the descriptor "salty".

The taste analysis results are presented in Table 3. The results show that odour and taste are very linked because the intensity marks according to the descriptors and the smoking process evolve similarly.

Taste of salmons smoked by liquid smoke are very different from the tastes obtained with techniques applying wood pyrolysis. For each descriptor, the remarks formulated for the odour analysis according to the different smoking techniques could be said again about the taste. The intensities of smoke and salmon-like tastes of products appear globally weaker than those of corresponding odours.

The difference in taste observed between salmons treated with liquid smoke and salmons smoked with the other techniques for the descriptor "salty" is interesting. Normally, as the salmons were salted according to the same procedure, the salty taste would have been similar for all the salmons. This difference could mean that liquid smoke causes not only odour interactions with the product but also generates physical interactions which influence the salty taste. As for odour analysis, the process of liquid smoke atomization can be implied but this is especially the composition of the liquid smoke that is responsible of this difference. This result allows also to conclude that wood smoke at gaseous state, produced according various devices and wood pyrolysis temperatures, seems to have the same effect on the salty taste. More generally, the three smoking processes applying wood pyrolysis leads to products quite similar in odour and taste. It means that whatever the wood pyrolysis, the smoke produced has a quite same odour and acts quite identically on the salmon flesh components.

The taste analysis does not bring a lot of additional information by comparison with the odour analysis in order to differentiate the processes. It only strengthens the homogenity of the three techniques applying wood pyrolysis to produce smoke and the marginality of liquid smoke.

\section{PAH assessment}

Concerning the PAH evaluation, except for benzo(a)pyrene, maximum residue limits are not available. Then, to assess the contamination of a smoked salmon, the TEQ (Toxic Equivalent Quantity) approach was chosen. TEQs are calculated by the multiplication of each PAH concentration by its corresponding TEF (Toxic Equivalent Factor). TEF consists in giving to each $\mathrm{PAH}$ a relative toxicity as a fraction of the most toxic one, benzo(a)pyrene. This strategy, chosen by AFSSA (Association Française de la Sécurité Sanitaire des Aliments) and INERIS (Institut National de l'Environnement Industriel et des Risques), is based on the principle that PAHs 
effects are additives, but not antagonist nor synergic, and that they have the same mechanism of toxic action ${ }^{18}$. Table 4 shows the TEFs for each of the PAHs targeted in this study. INERIS gives to benzo(j)fluoranthene the same TEF than benzofluoranthenes, i.e., 0.1. The different TEQs (calculated from INERIS table) and benzo(a)pyrene concentrations obtained for each smoking process are compiled in Table 5.

It is important to note that when smoke comes from wood pyrolysis the maximum residue limit of $5 \mu \mathrm{g} \cdot \mathrm{kg}^{-1}$ of benzo(a)pyrene fixed by the European Commission ${ }^{19}$ for smoked seafood products is never reached. Friction and smouldering seem to lead to the highest TEQ which are twenty times lower than the European limit value for benzo(a)pyrene concentration. Thermostated plates method leads to lower value of TEQ and has the weakest concentrations of benzo(a)pyrene. For these three smoking processes, benzo(a)pyrene has been evaluated at a concentration of $0.1 \mu \mathrm{g} \cdot \mathrm{kg}^{-1}$. This benzo(a)pyrene concentration is in accordance with others benzo(a)pyrene concentrations found in smoked fish which underlines the coherence of our results $20,21,22$. Liquid smoke technique allows to obtain the less contaminated smoked salmons. However, the legislation concerning this technique is different. The directive 88/388/EEC has limited the maximum residual levels of benzo(a)pyrene to $0.03 \mu \mathrm{g}^{\mathrm{kg}}{ }^{-1}$ in liquid smoke flavourings $23,24,25$. Our results show that if liquid smoke process reduces the individual PAH concentrations, benzo(a)pyrene concentration can reach, in certain conditions (1 or 2 hours of smoke exposure at $\left.32{ }^{\circ} \mathrm{C}\right)$, until three times higher this legal threshold $\left(0.09 \mu \mathrm{g} . \mathrm{kg}^{-1}\right)$.

It can be noted that when thermostated plates process is used, TEQ and benzo(a)pyrene concentration are very low for one hour of smoke exposure, compared to the others processes. This difference is not noticeable for two and three hours of smoke exposure. It is surprising because this process implies the highest pyrolysis temperature $\left(500{ }^{\circ} \mathrm{C}\right)$ and the temperature of wood pyrolysis has already been reported as determinant in PAHs generation in wood smoke. The PAHs quantity increases linearly according to the pyrolysis temperature between 400 and $1000{ }^{\circ} \mathrm{C}{ }^{1}$. In fact, smouldering and friction with pyrolysis temperature about $400{ }^{\circ} \mathrm{C}$ lead to the highest TEQ. Thermostated plates also but only after more than one hour of exposure to smoke. This phenomenon could show an inertia in thermostated plates process for the PAH generation which is not found for the others odorants of wood smoke because no consequent odour and taste difference between the three processes applying wood pyrolysis is noticeable.

For the four smoking processes, PAHs were studied at three times of smoking and at two temperatures of the smokehouse. An analysis of the variance was carried out and the results are compiled in table 5.

For smouldering smoking and liquid smoke process, the time of exposure and the temperature of the smokehouse seem not to influence PAH concentration because the analysis of the variance with TEQ and after with benzo(a)pyrene concentration as variables did not reveal possible impact of these factors at a risk $5 \%$.

For thermostated plates, the low levels of PAHs during the first hour of smoking are also shown in ANOVA results. Indeed, an effect of the time of exposure to the smoke is noticed to explain the differences between the content at 1 hour and the contents at 2 and 3 hours of smoking. For TEQ and benzo(a)pyrene, the longer is the smoking time, the higher PAHs concentration is. The same remark can be formulated for friction technique but TEQ and benzo(a)pyrene concentration were already high during the first hour of smoking.

The occurrences of PAH in the four smoking processes are nearly similar but the legislation between liquid smoke technique and the others is different. If liquid smoke is considered as flavouring process, the benzo(a)pyrene concentration recovered is higher than the legal value. 
Among the three others techniques, thermostated plates appears as the smoking process leading to the less contaminated samples.

It is important to note that indeno(1,2,3-c,d)pyrene, dibenzo(a,h)anthracene and all dibenzopyrenes were sometimes detected but it was never possible to quantify them.

\section{Conclusion}

The four most frequently used smoking processes have shown organoleptic, economic and sanitary differences. It is of considerable interest for processors to know the characteristics brought by a process to the product that they want to smoke. It is important to notice that there is not an ideal smoking process but each smoking process is enough different from the others to allow a choice according to the aims of the processor. According to the three parameters studied (odour, taste, PAHs occurrence and price of the smoke generation), liquid smoke atomization seems not to be enough controlled because the odours carried are too different from the other techniques, the costs are the highest and even if the total concentration of PAHs is lower than the other techniques, the benzo(a)pyrene is not under the $0.03 \mu \mathrm{g} . \mathrm{kg}^{-1}$ level. However, industrially, liquid smoke has other benefits for the storage for example, the decrease of accidents due to fires, the easiness of the vaporization. Among the three processes using wood pyrolysis, the costs do not constitute the critical parameter even if friction is a little more expensive due to the price of log. From a PAHs point a view, thermostated plates seem to be the process generating the lowest level of PAHs. Moreover the odorant profiles of smoked products obtained by these techniques are nearly similar. This type of work could be extended to other smoked food in order to better study a possible effect of the food matrix. The creation of smoked products odours and PAHs occurrence might be better understood by the study of their kinetics of deposition according to the parameters of smoking process.

\section{Acknowledgements}

Authors thank the trained panel of IFREMER for its precious work in the sensorial analysis, Régis BARON in all our discussions and the technical assistance of André DANIEL. Bruno VEYRAND and LABERCA are gratefully acknowledged for their technical help for PAHs analysis. 


\section{References}

1 Sainclivier, M. L'industrie alimentaire halieutique. Des techniques ancestrales à leurs réalisations contemporaines : salage, séchage, fumage, marinage, hydrolysats. Bulletin scientifique et technique de l'Ecole Nationale Supérieure Agronomique Centre de Recherches de Rennes, 219-285(1985).

2 Miller, K.B.M., Sikorski, Z.E. Smoking. In : Seafood : Resources, nutritional composition, and preservation. CRC Press, Inc., Boca Raton, Florida (1990).

3 Maga, J.A. The flavor chemistry of wood smoke. Food Rev. Int., 1\&2, 139-183 (1987).

4 Guillén, M.D., Sopelana, P., Partearroyo, M.A. Determination of polycyclic aromatic hydrocarbons in commercial liquid smoke flavorings of different compositions by gas chromatography-mass spectrometry. J. Agric. Food Chem., 48, 128-131 (2000).

5 Šimko, P., Brunckova, B. Lowering of polycyclic aromatic hydrocarbons concentration in a liquid smoke flavour by sorption into polyethylene packaging. Food Addit. Contam., 10(2), 257263 (1993).

6 Guillén, M.D., Sopelana, P., Partearroyo, M.A. Polycyclic aromatic hydrocarbons in liquid smoke flavorings obtained from different types of wood. Effect of storage in polyethylene flasks on their concentrations. J. Agric. Food Chem., 48, 5083-5087 (2000).

7 Yurchenko, S., Mölder, U. The determination of polycyclic aromatic hydrocarbons in smoked fish by gas chromatography mass spectrometry with positive-ion chemical ionization. Journal of Food Composition and Analysis, 18, 857-869 (2005).

8 Cardinal, M., Gunnlaugsdottir, H., Bjoernevik, M., Ouisse, A., Vallet, J.L., Leroi, F.. Sensory characteristics of cold-smoked atlantic salmon (Salmo salar) from European market and relationships with chemical, physical and microbiological measurements. Food Res. Int., 37, 181193 (2004).

9 Monteau, F., Sarcher, L., Varlet , V., Maume, D., André, F., Le Bizec, B. Compared mass spectrometry approches for PAH determination in food. Work presented at the Dioxin 2005 / ISPAC 20 congress, Toronto, Canada (2005).

10 European Commission . Official Journal of the European Union, L 34, 43-45 (2005).

11 Guillén, M.D., Ibargoitia, M.L. Relationships between the maximum temperature reached in the smoke generation processes from Vitis vinifera L. Shoot sawdust and composition of the aqueous smoke flavoring preparations obtained. J. Agric. Food Chem., 44, 1302-1307 (1996).

12 Knockaert, C. Le fumage du poisson. Service de la documentation et des publications, IFREMER, Brest (1990).

13 Varlet, V., Knockaert, C., Prost, C., Sérot, T. Comparison of odor-active volatile compounds of fresh and smoked salmon. J. Agric. Food Chem., 54, 3391-3401 (2006).

14 Cardinal, M., Cornet, J., Sérot, T., Baron, R. Effects of the smoking process on odour characteristics of smoked herring (Cuplea harengus) and relationships with phenolic compound content. Food Chem., 96, 137-146 (2006).

15 Nonier, M.F., Vivas, N., Vivas de Gaulejac, N., Absalon, C., Soulié, Ph., Fouquet, E. Pyrolysis-gas chromatography/mass spectrometry of Quercus sp. Wood. Application to structural elucidation of macromolecules and aromatic profiles of different species. J. Anal. Appl. Pyrolysis, 75(2), 181-193 (2005).

16 Cardinal, M., Berdagué, J.L., Dinel, V., Knockaert, C., Vallet, J.L.. Effect of various smoking techniques on the nature of volatile compounds and on the sensory characteristics of salmon meat. Sci. Alim., 17, 679-696 (1997). 
17 Kostyra, E., Baryłko-Pikielna, N. Volatiles composition and flavour profile identity of smoke flavourings. Food Quality and Preference, 17(1-2), 85-95 (2006).

18 Doornaert, B., Pichard, A., Gillet, C. Hydrocarbures aromatiques polycycliques (HAPs). Evaluation de la relation dose-réponse pour des effets cancérigènes: Approche substance par substance (facteurs d'équivalence toxique - FET) et approche par mélanges. Evaluation de la relation dose-réponse pour des effets non cancérigènes: Valeurs Toxicologiques de Référence (VTR). INERIS-DRC-03-47026-ETSC-BDo-N03DR177 (2003). 19 European Commission Official Journal of the European Union, L 34, 3-5 (2005b).

20 Kazerouni, N., Sinha, R., Hsu, C.H., Greenberg, A., Rothman, N. Analysis of 200 food items for benzo(a)pyrene and estimation of its intake in an epidemiologic study. Food Chem. Toxicol., 39, 423-436 (2001).

21 Storelli, M.M., Stuffler, R.G., Marcotrigiano, G.O. Polycyclic aromatic hydrocarbons, polychlorinated biphenyls, chlorinated pesticides (DDTs), hexachlorocyclohexane, and hexachlorobenzene residues in smoked food. J. Food Protection, 66(6), 1095-1099 (2003).

22 Stołyhwo, A., Sikorski, Z.E. Polycyclic aromatic hydrocarbons in smoked fish - a critical review. Food Chem., 91(2), 303-311 (2005).

23 European Commission. Official Journal of the European Union, L 184 (1988).

24 Šimko, P. Determination of polycyclic aromatic hydrocarbons in smoked meat products and smoke flavourings additives. J. Chromatogr. B., 770, 3-18 (2002).

25 Šimko, P. Factors affecting elimination of polycyclic aromatic hydrocarbons from smoked meat foods and liquid smoke flavorings. Mol. Nutr. Food Res., 49, 637-647 (2005). 
Table 1. Parameters of the four smoking techniques for three hours of smoke exposition.

\begin{tabular}{|c|c|c|c|c|}
\hline Parameters & Smouldering & $\begin{array}{c}\text { Thermostated } \\
\text { Plates }\end{array}$ & Friction & Liquid Smoke \\
\hline $\begin{array}{c}\text { Temperature of } \\
\text { pyrolysis }\end{array}$ & 400 to $450{ }^{\circ} \mathrm{C}$ & $500{ }^{\circ} \mathrm{C}$ & $380{ }^{\circ} \mathrm{C}$ & - \\
\hline Moisture of sawdust & $20 \%$ & - & $1.59 \mathrm{~kg}$ & $3 \mathrm{~L}$ \\
\hline $\begin{array}{c}\text { Quantity of wood } \\
\text { pyrolyzed (or liquid } \\
\text { smoke vaporized) }\end{array}$ & $1.69 \mathrm{~kg}$ & $1 \mathrm{~kg}$ & $180 \mathrm{~g}$ & - \\
\hline Ashes & $330 \mathrm{~g}$ & - & 3.08 & 7.62 \\
\hline $\begin{array}{c}\text { Price of wood raw } \\
\text { material used with } \\
\text { smouldering as } \\
\text { reference (euros) }\end{array}$ & 1 & 0.59 & 1.6 & $<0.1$ \\
\hline $\begin{array}{c}\text { Electric consumption } \\
\text { (KW/h) }\end{array}$ & 0.7 & 1.8 & & \\
\hline
\end{tabular}

For a smokehouse capacity of $380 \mathrm{~kg}$ 
Table 2. Characterization of the odour of smoked salmon according to the four smoking techniques

\begin{tabular}{|c|c|c|c|c|c|}
\cline { 2 - 5 } \multicolumn{1}{c|}{} & \multicolumn{4}{c|}{ Smoking processes } & \multirow{2}{*}{ P-value } \\
$\begin{array}{c}\text { Odorant } \\
\text { descriptors }\end{array}$ & Smouldering & Friction & $\begin{array}{c}\text { Thermostated } \\
\text { plates }\end{array}$ & $\begin{array}{c}\text { Liquid } \\
\text { Smoke }\end{array}$ & \\
\hline $\begin{array}{c}\text { Wood fire } \\
\text { Smoke }\end{array}$ & $5.29^{\mathrm{a}}$ & $5.67^{\mathrm{a}}$ & $5.33^{\mathrm{a}}$ & $2.79^{\mathrm{b}}$ & $<0.0001^{* * *}$ \\
\hline Cold smoke & $1.60^{\mathrm{b}}$ & $1.43^{\mathrm{b}}$ & $2.38^{\mathrm{b}}$ & $5.04^{\mathrm{a}}$ & $<0.0001^{* * *}$ \\
\hline butter & $1.33^{\mathrm{a}}$ & $1.73^{\mathrm{a}}$ & $1.30^{\mathrm{a}}$ & $0.24^{\mathrm{b}}$ & $0.0055^{* *}$ \\
\hline Vegetal (grass) & $0.45^{\mathrm{b}}$ & $0.32^{\mathrm{b}}$ & $0.47^{\mathrm{b}}$ & $1.52^{\mathrm{a}}$ & $0.0007^{* * *}$ \\
\hline Salmon & $3.59^{\mathrm{a}}$ & $3.46^{\mathrm{a}}$ & $3.06^{\mathrm{a}}$ & $1.51^{\mathrm{b}}$ & $<0.0001^{* * *}$ \\
\hline Herring & 0.95 & 0.71 & 1.00 & 0.65 & 0.4804 \\
\hline
\end{tabular}

Significant differences at : * $=5 \% * *=1 \%$, *** $=0,1 \%$.

The means followed by the same letter are not significantly different at $5 \%$. 
Table 3. Characterization of the taste of smoked salmon according to the four smoking techniques

\begin{tabular}{|c|c|c|c|c|c|}
\cline { 2 - 5 } \multicolumn{1}{c|}{} & \multicolumn{4}{c|}{ Smoking Processes } & \multirow{2}{*}{ P-value } \\
\hline $\begin{array}{c}\text { Taste } \\
\text { descriptors }\end{array}$ & Smouldering & Friction & $\begin{array}{c}\text { Thermostated } \\
\text { plates }\end{array}$ & $\begin{array}{c}\text { Liquid } \\
\text { Smoke }\end{array}$ & \\
\hline $\begin{array}{c}\text { Wood fire } \\
\text { Smoke }\end{array}$ & $5.61^{\mathrm{a}}$ & $5.71^{\mathrm{a}}$ & $5.58^{\mathrm{a}}$ & $3.03^{\mathrm{b}}$ & $<0.0001^{* * *}$ \\
\hline Cold smoke & $1.45^{\mathrm{b}}$ & $1.15^{\mathrm{b}}$ & $2.10^{\mathrm{b}}$ & $5.07^{\mathrm{a}}$ & $<0.0001^{* * *}$ \\
\hline butter & 0.93 & 1.00 & 1.20 & 0.46 & 0.16 \\
\hline Vegetal (grass) & $0.29^{\mathrm{b}}$ & $0.55^{\mathrm{b}}$ & $0.29^{\mathrm{b}}$ & $1.63^{\mathrm{a}}$ & $0.0015^{* *}$ \\
\hline Salmon & $3.96^{\mathrm{a}}$ & $4.04^{\mathrm{a}}$ & $3.75^{\mathrm{a}}$ & $2.94^{\mathrm{b}}$ & $0.001^{* * *}$ \\
\hline Herring & $0.73^{\mathrm{a}}$ & $0.76^{\mathrm{a}}$ & $0.85^{\mathrm{a}}$ & 0.61 & 0.76 \\
\hline Salty & $5.72^{\mathrm{a}}$ & $5.54^{\mathrm{a}}$ & $6.08^{\mathrm{a}}$ & $4.64^{\mathrm{b}}$ & $0.0005^{* * *}$ \\
\hline
\end{tabular}

Significant differences at : ${ }^{*}=5 \%{ }^{* *}=1 \%$, *** $=0,1 \%$.

The means followed by the same letter are not significantly different at $5 \%$. 
Table 4. TEF of the PAHs studied

\begin{tabular}{|c|c|c|}
\hline List of PAHs & TEF (INERIS) & TEF (Larsen et al., 1998) \\
\hline Fluorene & 0.001 & 0.05 \\
\hline Phenanthrene & 0.001 & 0.0005 \\
\hline Anthracene & 0.01 & 0.0005 \\
\hline Fluoranthene & 0.001 & 0.05 \\
\hline Pyrene & 0.001 & 0.001 \\
\hline Benzo(a)anthracene & 0.1 & 0.005 \\
\hline Cyclopenta(c,d)pyrene & 0.1 & 0.02 \\
\hline Chrysene & 0.01 & 0.03 \\
\hline 5-methylchrysene & & 0.1 \\
\hline Benzo(b)fluoranthene & 0.1 & 0.05 \\
\hline Benzo(j)fluoranthene & 0.1 & 0.05 \\
\hline Benzo(k)fluoranthene & 1 & 1 \\
\hline Benzo(a)pyrene & 0.1 & 0.1 \\
\hline Indéno(1,2,3-c,d)pyrene & 1 & 1.1 \\
\hline Dibenzo(a,h)anthracene & 0.01 & 0.02 \\
\hline Benzo(g,h,i)perylene & & 1 \\
\hline Dibenzo(a,l)pyrene & & 0.2 \\
\hline Dibenzo(a,e)pyrene & & 0.1 \\
\hline Dibenzo(a,i)pyrene & & 1 \\
\hline Dibenzo(a,h)pyrene & & 1 \\
\hline
\end{tabular}

TEF of 5-methylchrysene was only assessed for an aerial contamination and sat at 1 (Collins et al., 1998). 
Table 5. Toxic equivalent quantity and concentration of benzo(a)pyrene ( $\mu \mathrm{g} \cdot \mathrm{kg}^{-1}$ of wet weight) for the four smoking techniques.

\begin{tabular}{|c|c|c|c|c|c|c|}
\hline & \multicolumn{2}{|c|}{$1 \mathrm{hr}$} & \multicolumn{2}{|c|}{$2 \mathrm{hrs}$} & \multicolumn{2}{|c|}{$3 \mathrm{hrs}$} \\
\hline & $22^{\circ} \mathrm{C}$ & $32^{\circ} \mathrm{C}$ & $22^{\circ} \mathrm{C}$ & $32{ }^{\circ} \mathrm{C}$ & $22^{\circ} \mathrm{C}$ & $32{ }^{\circ} \mathrm{C}$ \\
\hline $\begin{array}{c}\text { TEQ } \\
\text { Smouldering }\end{array}$ & 0,099 & 0,112 & 0,119 & 0,123 & 0,106 & 0,140 \\
\hline [BaP] & 0,080 & 0,079 & 0,083 & 0,077 & 0,072 & 0,092 \\
\hline $\begin{array}{c}\text { TEQ } \\
\text { Thermostated } \\
\text { plates }\end{array}$ & $0,014^{a}$ & $0,016^{a}$ & 0,096 & 0,092 & 0,093 & 0,100 \\
\hline [BaP] & $\mathrm{nq}^{\mathrm{a}}$ & $\mathrm{nq}^{\mathrm{a}}$ & $0,072^{b}$ & $0,065^{b}$ & $0,069^{b}$ & $0,070^{b}$ \\
\hline $\begin{array}{l}\text { TEQ } \\
\text { Friction }\end{array}$ & 0,093 & 0,090 & 0,112 & 0,107 & 0,137 & 0,125 \\
\hline [BaP] & $0,074^{b}$ & $0,071^{b}$ & $0,089^{C}$ & $0,081^{C}$ & $0,111^{d}$ & $0,097^{d}$ \\
\hline $\begin{array}{c}\text { TEQ } \\
\text { Liquid smoke }\end{array}$ & 0,076 & 0,102 & 0,078 & 0,098 & 0,060 & 0,064 \\
\hline [BaP] & 0,047 & 0,085 & 0,064 & 0,084 & 0,047 & 0,047 \\
\hline
\end{tabular}

The means followed by the same letter are not significantly different at $5 \%$.

TEQs were calculated with the INERIS TEFs (Table 4). 